NBER WORKING PAPER SERIES

SOCIAL IMPACT BONDS IN NONPROFIT HEALTH CARE:
NEW PRODUCT OR NEW PACKAGE?

\author{
Mark Pauly \\ Ashley Swanson \\ Working Paper 18991 \\ http://www.nber.org/papers/w18991 \\ NATIONAL BUREAU OF ECONOMIC RESEARCH \\ 1050 Massachusetts Avenue \\ Cambridge, MA 02138 \\ April 2013
}

The views expressed herein are those of the authors and do not necessarily reflect the views of the National Bureau of Economic Research.

NBER working papers are circulated for discussion and comment purposes. They have not been peerreviewed or been subject to the review by the NBER Board of Directors that accompanies official NBER publications.

(C) 2013 by Mark Pauly and Ashley Swanson. All rights reserved. Short sections of text, not to exceed two paragraphs, may be quoted without explicit permission provided that full credit, including $\odot$ notice, is given to the source. 
Social Impact Bonds in Nonprofit Health Care: New Product or New Package?

Mark Pauly and Ashley Swanson

NBER Working Paper No. 18991

April 2013

JEL No. H0,H51,I1,I10,I13,I18

\section{ABSTRACT}

This note considers a relatively new form of financing for social services, the "Social Impact Bond." Proponents of Social Impact Bonds argue that they present a solution to several problems in funding social services, including performance measurement and the distribution of risk. Using a simple model, we demonstrate that Social Impact Bonds have many features present in standard financing arrangements. They will lead to greater program success when investors' effort can positively influence outcomes, but are unlikely to do so otherwise. We conclude that the value of this funding innovation will be strongly context-dependent.

Mark Pauly

Health Care Management Department

The Wharton School

University of Pennsylvania

208 Colonial Penn Center

3641 Locust Walk

Philadelphia, PA 19104-6218

and NBER

pauly@wharton.upenn.edu

Ashley Swanson

Health Care Management Department

The Wharton School

University of Pennsylvania

302 Colonial Penn Center

3641 Locust Walk

Philadelphia, PA 19104-6218

aswans@wharton.upenn.edu 


\title{
Social Impact Bonds in Nonprofit Health Care: New Product or New Package?
}

\author{
Mark Pauly and Ashley Swanson
}

April 16, 2013

\begin{abstract}
This note considers a relatively new form of financing for social services, the "Social Impact Bond." Proponents of Social Impact Bonds argue that they present a solution to several problems in funding social services, including performance measurement and the distribution of risk. Using a simple model, we demonstrate that Social Impact Bonds have many features present in standard financing arrangements. They will lead to greater program success when investors' effort can positively influence outcomes, but are unlikely to do so otherwise. We conclude that the value of this funding innovation will be strongly context-dependent.
\end{abstract}

\section{Introduction}

Substantial attention is currently focused on innovative funding models for social services. Proponents of social funding innovation note that government funding of social programs is rife with weaknesses, including 1) insufficient attention to measurement of outcomes of interest, resulting in persistence of ineffective programs; 2) slow and/or limited adoption of innovative approaches; and 3) service providers' inability to bear the upfront invest- 
ment costs and financial risk of performance-based contracts. See Liebman (2011) for a discussion. One investment product that is the object of particular notice currently is the so-called "Social Impact Bond (SIB)", which has the following features: 1) the upfront capital is provided by private investors, effectively insulating service providers from financial risk; 2) a measurement and evaluation procedure is inherent in the product, as the government only pays back investors if pre-specified performance targets are met according to a specific timeline; 3) the performance contingency also makes innovative social interventions more viable in the eyes of risk-averse government officials; and 4) external investment helps strained government budgets.

Several SIB projects are currently underway in the United States and elsewhere. In the United Kingdom, the London-based nonprofit Social Finance has set up an SIB in which private investors (including the United Kingdom lottery and the Macarthur Foundation) have supplied $\$ 7.9$ million to finance a program to reduce Peterborough Prison inmate recidivism rates. If the program, administered by the nonprofit St. Giles trust, successfully reduces recidivism rates in its treatment group by $7.5 \%$ relative to a control group (male inmates are 60\% likely to reoffend within one year without intervention), the United Kingdom Justice Ministry will pay back the initial investment plus a small return, which increases if rates are further reduced beyond the target threshold. ${ }^{1}$ A similar program is in early stages in New York City - Goldman Sachs will provide $\$ 9.6$ million to implement a recidivism-reduction program targeted to Rikers Island adolescent inmates provided by MDRC, a nonprofit education and social policy research organization; in this case, $75 \%$ of the investment is guaranteed by Bloomberg Philanthropies and the government payer is New York City's Department of Corrections. ${ }^{2}$

SIB projects currently in progress are generally devoted to reducing government spending on social services such as corrections and homelessness, but SIB advocates

\footnotetext{
${ }^{1}$ Liebman (2011).

${ }^{2}$ Chen (2012).
} 
are hoping to expand the scope of SIB programs, particularly toward health care. Paul Corrigan of Britain's National Health Service London Strategic Health Authority has argued that SIBs would be an effective way of financing programs to manage diabetes and asthma for NHS patients. ${ }^{3}$ Last December, the New Jersey Assembly passed the NJ Social Impact Bond Act, which seeks to attract private funding for public programs aimed at reducing the cost of providing healthcare to low-income and uninsured residents. ${ }^{4}$ In California, Social Finance is in early stages of a program to reduce emergency room visits and hospitalizations among Fresno children with asthma. ${ }^{5}$

While the interest surrounding innovative ways to provide crucial social services is encouraging particularly in a time of upheaval for our nation's health care system, several questions remain about whether SIBs have greater promise for efficient investment and efficient performance than with more traditional funding models. In this note, we consider a simple model of a social program with stochastic success and identify the assumptions under which social impact bonds will increase the likelihood of program success over what would happen under traditional for profit and nonprofit funding models.

\section{Model}

Consider a model in which the government values a successful social program (e.g., reduction in recidivism rates by $7.5 \%$ ) at $b$, but for political reasons cannot make funds available for the program prior to proven success. Suppose that a service provider (nonprofit or for-profit) can implement the program and achieve success with probability $p$; the up-front cost of the program, which takes one period to implement, is $X$. Suppose also that there is a large number of private investors, some of whom are altruistic; both hold diversified portfolios and so are risk-neutral with respect to any single project. The

\footnotetext{
${ }^{3}$ Corrigan (2011).

${ }^{4}$ NJ Fifth Legislative District (2012).

${ }^{5}$ Jensen (2013).
} 
non-altruistic investors require the market return $r$ per dollar invested and do not care which type of company they invest in, while the altruistic investors require the return $a<r$, but will only invest in or donate to nonprofits. ${ }^{6}$

The expected benefit of the program is $p * b-X$, so the program should be implemented if $p>X / b$. Suppose this is so. We then can distinguish several cases.

If $p * b \geq(1+r) * X$, then the program can be implemented by a competitive for-profit service provider issuing equity to non-altruistic investors.

Assume that $(1+a) * X=p * b<(1+r) * X$, so that the altruistic investors would be just willing to provide complete funding for the project, while non-altruistic investors would not. In this case, the nonprofit organization can provide the service and the altruistic investors are willing to invest; however, the nonprofit cannot issue conventional equity, so there may be a barrier to financing. Here, the social impact bond model provides a solution; the nonprofit and altruistic investors can contract jointly with the government, specifying the payment rule (payment of $b$ to the investors in case of program success) and financing ( $X$ paid to the nonprofit up front). The program is implemented and the expected benefit to society is $p * b-X>0$. The investors then receive a nominal return per dollar invested of $c$, so that $p(1+c) X=(1+a) X$.

What the above analysis ignores is that nonprofit organizations are not so constrained in their financing options as the model supposed. In fact, nonprofit organizations quite often offer bonds. While these bonds promise to return interest and principal, default is possible if the nonprofit firm does not earn enough to make those payments. In such cases, the bonds are rated as lower quality, and sometimes as "junk." In this stylized setting, the nonprofit can offer several products:

- A bond with the promised return of $b$ in case of program success and 0 (default) in case of failure. That is, this bond promises a nominal return per dollar of $c$ which

\footnotetext{
${ }^{6}$ See Pauly (1973) and Glaeser and Shleifer (2001) for a discussion of the role of nonprofits and for-profits in enterprise.
} 
satisfies $(1+c) X=b=((1+a) X) / p$. Given our above assumptions, this bond would be acceptable to altruistic investors and the program would be implemented (essentially mimicking the SIB but without involving investors in the government contract directly).

- The nonprofit could sell bonds to non-altruistic investors and make up the shortfall in their required return with donations from the altruistic investors equivalent to the donation embodied in the social impact bond. That net donation in the case of SIB is $(r-a) X$. Call this amount $D$ and imagine it is made as an initial lump sum donation to the nonprofit firm that will receive the government contract. The nonprofit then borrows $X$ from non-altruistic donors, promising to pay them $\left(1+r^{\prime}\right) X+D$ if the program succeeds, with $r^{\prime}=\frac{1+a}{p}$, and $D$ if the program fails. Since $p\left(1+r^{\prime}\right) X=(1+a) X$, it follows that the expected return to the non-altruistic investors is $(1+a) X+(r-a) X$, or $(X+r X)$, their required return. The value of $r$ is the same as the value of $c$ in the previous case. However, the "donation" in this case is paid to the non-altruistic investors whether or not the project succeeds. (Investors could agree to receive nothing if the project fails but then the nonprofit would have to pay $D / p$ if success occurs; it would have to "insure" the donation.)

- Another equivalent option would be a bond paying $b$ in case of success and $g$ in case of failure, the $g$ being supplied by an altruistic investor acting as guarantor as in the Bloomberg arrangement described above. The altruistic investor is willing to guarantee the bond if $(1-p) * g \leq(r-a) * X$ and the non-altruistic investors are willing to purchase the bond if $p * b+(1-p) * g \geq(1+r) * X$. The conditions on the model parameters for an implementable bond to exist are identical for implementability of a SIB.

These examples show that equity and debt arrangements can be mathematically just as attractive as the SIB. Further, if the SIB is even $\epsilon$ more costly (than using an already 
existing nonprofit firm) to set up due to complicated legal arrangements, it is strictly dominated by more standard financing. Hence, some modification to the model is needed to justify preference for an SIB over standard methods.

Suppose, for instance, that $p$ is not fixed, but rather an increasing function of outsider effort (e.g., through monitoring of the service provider's efficiency) $p(e)=\bar{p}+m * e$ with $m>0 .{ }^{7}$ Suppose also that only altruistic investors are willing to provide effort of this sort; managers of nonprofit firms are not, and non-altruistic investors are not. Consider the case where $\bar{p} * b<(1+a) * X$. Obviously, since $r>a$ the service cannot be provided by a for-profit with non-altruistic investors, because the return will not be high enough, absent positive outsider effort. Consider the implementability of the program under debt arrangements with a nonprofit service provider:

- A bond with the promised return of $b$ would not be accepted by altruistic investors because an arm's length debt arrangement does not allow for creditor involvement in issuer activities.

- Next consider a bond with the promised return of $b+D$ in case of program success and $D$ in case of failure, with altruistic investors supplying the initial capital $D$. As a donor, the altruistic investor may be able to affect the probability of success (as, for example, a board member). Implicit in the lower required return $a$ for the altruistic investor is that the altruistic investor has some value $v$ for the social program beyond the expected government payment. ${ }^{8}$ If the entrepreneur has disutility of effort $f(e)$, then if the program is financed she will exert effort $\hat{e}$ such that the marginal return to effort $v * m$ equals the marginal cost $f^{\prime}(\hat{e})$. If for example $f(e)=e^{2}$, then effort supplied will equal $\frac{v * m}{2}$. The altruistic investor will be willing to donate $D$

\footnotetext{
${ }^{7}$ As noted by Conning and Morduch (2011), large-scale social investors typically provide both cash grants and specialized technical assistance. In the case of microfinance, social investors "take seats on the microlenders' boards, help shape governance, and transfer banking knowledge. It is the combination of capital and active engagement that has done the most to encourage additional private commercial funding and effectively expand the reach of markets."

${ }^{8}$ Mathematically, $a=r-\frac{p * v}{X}$.
} 
to this arrangement if $(\bar{p}+m * \hat{e}) * v \geq D$ - in our specific example, this requires $\bar{p} * v+\frac{(m * v)^{2}}{2} \geq D$. The wedge between this debt-plus-donation contract and the pure debt to altruistic investors contract is thus $\frac{(m * v)^{2}}{2}$ from the altruistic investors' perspective. The other requirement is that $b *(\bar{p}+m * \hat{e})+D \geq(1+r) * X$, so that the additional effort relaxes the constraint on obtaining non-altruistic investment capital as well. ${ }^{9}$

We saw above that debt-plus-donation dominates pure debt when effort by an altruistic donor increases the probability of success. Now consider the SIB model. In this case, the altruistic investor receives payout $(b+v) *(\bar{p}+m * e)-f(e)$ after investing, and thus will choose effort $\tilde{e}$ such that $f^{\prime}(\tilde{e})=m *(b+v)$. For example, in the case above where $f(e)=e^{2}, \tilde{e}=\frac{m *(b+v)}{2}>\frac{m * v}{2}=\hat{e}$ and greater effort will be provided under the SIB than under the debt-plus-donation setup or the pure debt contract. This result is due to our assumption of convex effort cost - if the disutility for effort were linear, the comparison of models would be discontinuous depending on the parameter values.

This result, in which effort disutility functions imply higher likelihood of success under the SIB model than under alternative financing options, has a certain intuitive appeal - when an agent is interested in both investment potential and social value, there is a multiplier effect such that she will exert more effort than if she were interested in the social value alone. This suggests that the SIB's inherent improvement over alternative models, if any, lies in involving altruistic investors in the process of providing the service without violating the non distribution constraint imposed on nonprofits. Put another way, in the case of the nonprofit firm, its management may have no desire to make effort to increase $p$, and the donors who have already made a donation may have neither incentive nor

\footnotetext{
${ }^{9}$ This assumes that the altruistic investor/donor values program success in addition to her own return on investment; other models could assume that the altruistic investor/donor is willing to accept a lower return on investment regardless of probability of success. For example, an image motivation model in which altruistic investors value being observed to donate to particular causes could be applicable in some settings. In such a case, the debt-plus-donation contract would not induce additional effort relative to the pure debt contract.
} 
ability to influence how the project is then constructed, whereas the SIB has donors with both the incentive and the power to affect $p$.

Of course, effort is not the only consideration. The management of a nonprofit firm probably has greater managerial skill than investors (altruistic or not). Moreover, we have assumed that altruistic investor effort can only raise $p$, while in reality investors and managers can have conflicting viewpoints in operational matters. So, as between SIB and the nonprofit firm model, there may be a tradeoff between effort to raise $p$ and skill in raising $p$, with the ideal depending on which influence is stronger.

Finally, if there are administrative costs to defaulting on bonds sold to non-altruists (even if they are offered as risky bonds), but lower such costs with the SIB model, that feature as well may favor SIB.

\section{Conclusion}

Viewed purely as a vehicle for financing projects paid under performance contracts, we have shown that social impact bonds need be no different than other more conventional methods of finance used by nonprofit firms. The innovation in social impact bonds, if there is one, must come from an hypothesized greater ability to solve the agency problem. In a sense, this is tautological: if the funders of social impact bonds are altruistic financiers with management skills in the project at hand - say, dealing with prison or diabetic populations - that arrangement will be the best. But the relationship between willingness to make altruistic efforts and skills in doing so is generally unknown, and surely variable. At the extreme, altruistic and financial goals may come into conflict during program implementation. Consider, for example, the micro loan investment sector, which, other than being explicitly focused on for-profit enterprise is fairly similar in structure to the SIB form. There were an estimated approximately $\$ 40$ billion in micro finance loan portfolios in 2008 (Rhyne, 2010), but the large Indian sector was in severe crisis in 2011 due to 
accusations of aggressive loan collection practices, over-lending to indebted customers, and exploitative interest rates (Conning and Morduch, 2011). Given the likely variable effect of effort on outcomes, the desirability of SIB's relative to other ways of financing and managing the supply of publicly demanded services is an open empirical question. Expanding the set of investment arrangements in itself is doubtless desirable, but not all innovations necessarily work out well. 


\section{References}

Chen, D. W. 2012. "Goldman to Invest in City Jail Program, Profiting if Recidivism Falls Sharply." The New York Times A14.

Conning, J. and Morduch, J. 2011. "Microfinance and Social Investment." Annual Review of Financial Economics 3(2) 407-434.

Corrigan, P. 2011. "Social Impact Bonds: A New Way to Invest in Better Healthcare." Social Finance September.

Glaeser, E. L. and Shleifer, A. 2001. "Not-For-Profit Entrepreneurs." The Journal of Public Economics. 81 (1): 99-115.

Jensen, R. 2013. "'Social Impact Bond' Buzz Heads West." The Bond Buyer. Available at http://www.bondbuyer.com/issues/122_8/fresno-california-pilot-project-social-impact-bonds1047541-1.html.

Liebman, J. B. 2011. "Social Impact Bonds: A Promising New Financing Model to Accelerate Social Innovation and Improve Government Performance." Center for American Progress.

New Jersey Fifth Legislative District. 2012. "Fuentes Social Impact Bill Advanced by Assembly Panel." Available at http://www.politickernj.com/61532/fuentes-social-impactbill-advanced-assembly-panel.

Pauly, M. V. and Redisch, M. 1973. "The Not-For-Profit Hospital as a PhysiciansÕ Cooperative." The American Economic Review 63(1) 87-99.

Rhyne, E. 2010. "The State of Global Microfinance: How Public and Private Funds Can Effectively Promote Financial Inclusions for All." Subcommittee on International Monetary Policy and Trade Committee on Financial Services U.S. House of Representatives. 